\title{
Snr. Alexandre Correia (1)
}

\section{Tristão de Athayde}

Permite-me o generoso desacêrto desta admirável mocidade universitária católica de S. Paulo - que me incumbiu de saudar-vos nesta manifestação de estudantes, - a honra de falar neste recinto.

E' preciso, talvez, não ser paulista, para sentir ou avaliar ao menos, a emoção com que um brasileiro de outro qualquer ponto do país, ou de sua capital, como eu, atravessa os humbrais desta velha casa, que a vossa energia e o vosso bom gosto, souberam rejuvenecer com tanto amor.

Esta Faculdade e a de Recife, foram, por meio século, as maiores formadoras de quasi todos os nossos grandes homens. Do sonho universitário de 1823, em que se empenhou com todo o seu vigor intelectual e moral, o grande e ainda mal conhecido Cayrú, sobrenadaram êsses dois Institutos jurídicos, em cujos recintos se preservaram os germens mais preciosos da nossa cultura.

$\mathrm{E}$ em todos nós que veneramos esse patrimônio de honestidade intelectual que constituiu a maior herança de nossos maiores, é considerável o prestígio desta Faculdade, em cujo espirito e sob cujo této se formaram gerações e gerações de juristas, magistrados, políticos, poetas, professores de todo o Brasil, guardas e testemunhas da nossa aristocracia cultural.

Somos um povo pobre. Nossa civilização, em contraste com outras, mesmo do nosso continente, não pode ostentar o mesmo grau de progresso material. E quem volta de alguma viagem ao estrangeiro, sente por vezes, com inquietação, o empirismo de nosso aparelhamento técnico ou administrativo.

(1) Conferência pronunciada na sala João Mendes, no dia 27 de Abril do corrente ano ás 20,30 horas, por ocasião da solenidade com que a A. U. C. (Ação Universitária Cat6lica) quiz homenagear o Prof. A. Correia, pela sua recente nomeação para cate. drático de Direito Romano, da Faculdade. 
Corre, porém, em nossas veias, uma linhagem intelectual que povos mais ricos e pedoresos não possuem. E no ponto que aqui particularmente nos interessa, temos em nossas mãos e sôbre os nossos ombros, a responsabilidade de uma herança de valor inestimável, que está ligada, em grande parte, a êste glorioso Instituto, honra de nosa tradição cultural e penhor de nosso futuro nacional. Essa herança que nos foi legada por todo o passado brasileiro e muito particularmente pelo Brasil Imperial, é o que podiamos chamar - a fé juridica.

Não somos um povo de espírito guerreiro. Não somos uma cicilização de estílo econômico. Não possuimos como temas essenciais de nossa história, nem a orquestração belicosa de uns, nem o vigor prátíco e utilitário de outros. Somos um povo pacífico, que ama as coisas desinteressadas. Somos um povo idealista que acredita na inteligência. Somos um povo até mesmo de coração excessivamente sensivel. E lutamos a cada passo contra os defeitos de nossas qualidades. Pois um dos sinais característicos da civilização brasileira é transportar para a vida coletiva as virtudes que ornam de preferênca as almas individuais: o desprendimento, a honradez, a bondade, a doçura, a polidez. Esse deslocamento de clima psicologico, da vida do indivíduo para a coletividade, redunda por vezes nos defeitos que acompanham o desequilibrio dessas qualidades.

Essa psicologia sumária, mas creio que correta do nosso povo, basta para indicar que não somos uma civilização marcial nem técnica, por excelência (apesar deste ou daquele êxito parcial, nesses terrenos) - e sim uma civilização essencialmente cultural e jurídica. o amor das letras e a confiança no direito - foram heranças que recebemos dos nossos antepassados e que poderiamos estudar, se tempo houvesse, não só em cada estação da história do nosso povo, mas em suas correspondências psycológicas com a vida interior de nossas almas.

Pois bem, se é isso o que nos revela um estudo, mesmo apressado, da nossa tradição nacional, manifesta-se entre nós, nos dias que correm, um fenômeno social, que é de molde a nos causar as mais sérias apreensões, pois vem contradizer aquela confiança no direito que é um dos postulados da nossa tradição e um leit-motiv da nossa psicologia coletiva.

Quero referir-me a um mal, que dia a dia se agrava em nosso meio - o ceticismo juridico.

Como o nome está indicando, distingui-se o ceticismo jurídico pela perda de confiança no direito, pelo desamor de seu estudo, pelo seu desprestígio. Não é difícil diagnosticar a existência dêsse mal em muitos dos nossos meios sociais, convindo frisar que não é um 
fenômeno desses dias mais recentes, pois ha muito se vem lentamente processando, embora se tenha ultimamente acentuado.

Vejamos ràpidamente as manifestações e as causas dêsse fenômeno que tão de perto afeta os fundamentos da civilização brasileira, em suas particularidades específicas.

Nos meios acadêmicos, manifesta-se o ceticismo jurídico pelo desinterêsse no estudo do direito e a sua pragmatização. Não sei o que se passa aqui entre nós. No Rio, posso assegurar que o ceticismo jurídico das últimas gerações se tem formado nos próprios bancos escolares. Eu mesmo posso dar o testemunho vívido de que os meus cinco anos de estudo do Direito foram, para mim e para a maioria de meus colegas, creio eu, um absoluto descalabro jurídico.

Saí da Faculdade inteiramente desinteressado pelo estudo do direito. A idéia que nos fora incutida, pelo agnosticismo jurídico ja então reinante na Faculdade, é que o direito era apenas uma serie de determinações arbitrárias do Estado, cristalizadas em textos positivos de lei, que em tese regulavam a vida em sociedade, mas que, na prática, defendiam apenas os intieresses individuais. E os juristas, magistrados, advogados, escrivães, etc., uma classe de espírito confinado e particularista, destinada a interpretar e aplicar com uma hermeneutica, mais ou menos hermética e sibilina, os textos secos da lei positiva. O positivismo jurídico nos arranca, desde os bancos acadêmicos, toda ilusão jurídica. Viamos erradamente o Direito, como uma secreção dos códigos e decretos, numa função de puro utilitarismo individualista. Pois nos proclamavam, em todos os tons, a morte do Direito Nacional, a separação entre o Direito e a Moral, o anacronismo radical da "Escola Teológica", como diziam, e a proclamação de um xaroposo ecletismo, que era o meio da "cadeira" não tomar partido. "Et pour cause"... E pelo que todos sabem, o mal nestes ultimos vinte anos só se tem agravado.

O estudo do Direito, portanto, fôra para mim, ha vinte anos, a morte do Direito e de todas as ilusões jurídicas. E só mais tarde, num esfôrço individual de vencer os preconceitos hauridos na Escola, é que vim a compreender o que era o Direito, é que vim a sentir a sua ligação com a vida, a riqueza do seu significado, a sua impregnação de humanidade, o sentido de sua universaldade, de sua beleza, e de sua fôrça moral. O Direito ressuscitou em mim quando me libertei do naturalismo juridico. Mas o mal dessa mutilação do Direito nas escolas, se estendeu a todas as novas gerações, de modo que é nos próprios meios acadêmicos, onde deviamos encontrar, bem fresco, o entusiasmo pelo Direito, que já vamos encontrar, em plena expansão, a mais inequívoca incredulidade a seu respeito. A impiedade juridica, em certos meio acadêmicos, é um mal tão grave e 
disseminado, como a impiedade religiosa. E as conseqüências sociais serão um dia tão graves talvez como as desta ultima.

Fora dos meios acadêmicos não é menos seria a extensão do ceticismo jurídico.

Nos meios sociais é considerável. A sentença popular, de que mais vale um mau acôrdo que uma boa demanda, é voz corrente em toda a parte. Perdeu-se, geralmente, a confiança na justiça civil, considerada como tardia e dispendiosa. E como o sentimentalismo da justiça penal, particularmente do juri popular, longe de ser uma barreira à criminalidade, tendo a ser cada vez mais um estímulo ao crime - também em relação a esta perdeu-se a confiança na justiça.

Nos meios políticos, ha uma oscilação entre dois fenômenos contrários, bem típicos do Brasil de nossos dias - o tenentismo e o bacharelismo.

Aquele, que vigorou de 1930 a 1934 e hoje ainda irrompe, por vezes, em manifestações vesanicas, é a expressão política revolucionária dêsse mesmo ceticismo juridico.

E êste, o bacharelismo, é a permanência de um fenômeno que precede e provoca, em geral, o ceticismo jurídico: o exagêro do Direito. ISe o tenentismo representa uma atrofia do Direito, representa o bacharelismo, sua hipertrofia. 0 mal do ceticismo jurídico provém, em geral, dêsse mal contrário, do hiperjuridicismo. 0 tenentismo se formou contra o bacharelismo. A descrença no Direito se elabora como reação contra uma excessiva confiança no Direito, motivada por uma falsa concepção de sua natureza científica. Fomos, por exemplo, em nossa adolescência, entusiastas de Ruy Barbosa. E depois seus i.conoclastas, na mocidade. Por quê? Porque ao nosso lírismo jurídico, que era falso, sucedeu como reação, o ceticismo jurídico, que não era menos falso. A um erro respondeu outro erro. E os dois coexistem em nossos meios políticos de hoje.

O outubrismo de 1930 foi uma forma de ceticismo juridico. A reconstitucionalização de 1934 - se não fôr compreendida e completada por uma reação moral e religiosa profunda e nacional pode vir a ser uma volta à credulidade jurídica, não menos errada e perniciosa que a descrença do direito. Pois da mesma forma que a credulidade religiosa é a negação da verdadeira Fé, - a credulidade juridica também é uma deturpação profunda do Direito. E a sua conseqüência é, fatalmente, a volta ao ceticismo juridico, e daí, lògicamente, à negação do Direito, tal como a vemos na concepção materialista do Direito, que é a sua subordinação à Revolução, isto é, à Força bruta ou ao Arbítrio Partidário.

Pois essa oscilação entre a hypertrofia do direito, que se espalha em regra nos regimes democratico-liberais e a atrofia jurídica dos 
regimes revolucionários ou das frases para-revolucionárias como a nossa de hoje em dia - é proveniente de uma falsa concepção do Direito.

A evolução histórica do mundo moderno, em relação ao Direito, tem sido uma marcha contínua à sua negação, pelo desconhecimento sucessivo de sua natureza.

O direito, em sua concepção integral, é uma expressão da Lei Eterna, da Lei Natural e da Lei Positiva. Só a primeira é imutável. A lei natural é estável, como a natureza humana, mas não imutavel. E a lei positiva varía com as condições sociais de sua aplicação aos povos, aos regimes e aos tempos diferentes.

A primeira mutilação que uma falsa filosofia imprimiu ao Direito, foi a supressão da Lei Eterna, que se confunde com a própria vida divina e o deslocamento dessa imutabilidade, que só o Bem Absoluto possue, para a razão natural do homem. Dai o falso direito natural do século XVIII, que desconhecia a natureza humana, dando-lhe atributos particulares à vida divina. 0 binômio Lei Natural-Lei Positiva, a que o racionalismo do século XVIII reduziu o Direito foi o início da hypertrofia do Direito, que está intimamente ligada, na vida polítiva dos povos, à ascensão do Liberalismo e da Democracia. O Direito adquire então uma autonomia, que se converte em expressão máxima da vida social. Tudo se subordina ao Direito. O Direito passa a ser a medida de todas as coisas. A salvação das sociedades passa a estar na supremacia absoluta da Lei, na tirania da Lei, no fetichismo da Lei. E essa lei, desligada da Fonte Suprema de todas as coisas, passa a ser uma potência moral da própria razão humana, abstrata, intangivel, imutável, única e invariável em todos os meios e em todos os tempos.

Contra êsse subjetivismo jurídico, ergue-se então a escola histórica, deslocando o direito do individuo para a coletividade, chegando, naturalmente, a uma nova mutilação do conceito integral do Direito: a supressão da lei natural.

De rigido, imutável, idêntico em suas bases, invariável em seus principios permanentes, e racionais, - passal o direito a ser efêmero, inconsistente arbitrário, méra secreção da sociedade, simples produto natural da história. E da escola histórica à escola sociológica, passando por toda a sorte de variações, dentro da mesma lendêncila inicial, passal o naturalismo jurídico a ver no Direito apenas a Lei Positiva. O Direito Eterno e o Direito Natural passam a ser julgados como méras fantasias de uma metafísica anacrônica e ultrapassada. E o direito a ser apenas o que a lei positiva determina.

Da mesma forma, porém, que se deslocara a invariabilidade da Lei Eterna para a Lei Natural, fizeram o mesmo os juristas burgue- 
zes, deslocando essa invariabilidade da Lei Natural para a Lei Positiva. As Constituições foram julgadas então intangíveis. $E$ os Códigos, depositórios últimos de toda a sabedoria. A vida dos povos parecia regulada, para sempre, por leis eternas. Não de uma eternidade "teológica" ou "metafísica", como diziam com desprezo os positivistas jurídicos, aludindo à Lei Eterna e à Lei Natural que julgavam ter abolido para sempre, - mas de uma intangibilidade positiva, pois a lei do progresso era apenas "a passagem do direito da fôrça para a força do direito". E esta era eterna e intangível, nas Constituições, nos Códigos, e nas Leis dos Parlamentos Democráticos. O Papa não era mais infalível. O Povo é que passava a ser infalível. E a infalibilidade do Povo é o dogma fundamental da Liberal-Democracia.

Daí ao socialismo, como a história moderna nos ensina, foi apenas um passo. $\mathrm{E}$ quando falo em socialismo, refiro-me a todas as suas nuances desde o socialismo mascarado que prolifera nos parlamentos liberais, até o socialismo integral dos comunistas.

E, na concepção do Direito, essa passagem do liberalismo ao socialismo, representou aquela oscilação acima apontada entre a hipertrofia do direito e a sua atrofia, entre o lirismo e o ceticismo jurídico.

Pois o socialismo reduz o direito, como a religião, a arte, a filosofia, e tudo mais, a ser apenas uma expressão das condições econômicas dominantes. E o socialismo proletário leninista não a guarda - provoca as mutações sociais, e portanto altera, à sua vontade, os regimes do direito. 0 direito passa a ser apenas um instrumento de dominio de um classe ou de um partido, e subordinado integralmente aos fins politicos da Revolução.

Processa-se assim na mente dos socialistas revolucionários e na prática da Revolução Integral, o aniquilamento teórico do direito, em sua autonomia, e sua subordinação total à política e à econômia.

Passou-se, portanto, naturalmente, de um excesso a outro, do monopólio do direito - como poder do homem, como proteção do indivíduo - à servidão do direito, que perde a sua autonomia e dissocia-se totalmente de sua fonte imediata - a Justiça, para ser uma expressão apenas do arbítrio político e revolucionário.

0 resultado de toda essa evolução do Direito no terreno político, é aquele mesmo ceticismo jurídico que fomos encontrar em setores do pensamento e da vida. E poderiamos continuar nesta analise, se a extensão destas palavras não nos advertisse de que devemos encurtá-las.

Perdoai, Sr. Alexandre Correia, se a concatenação das idéias. me levou mais longe do que tencionava de inicio. Quis acentuar, nesta hora de luta e de confusão, a gravidade de um mal que se 
espalha, por toda a parte, e que destrói o nosso amor ao Direito. E acentuar a sua contradição, nâo só em relação a todo o sentido do nosso passado nacional, mas ainda às exigências de uma sã filosofia da vida e da sociedade. Pois é no Direito que se funda toda a convivência social justa e civilisada, como é no Direito que assenta a grandeza e a solidez dos Estados. Não porém no Direito individualista e efêmero, filho de uma concepção mutilada da vida e das instituïções políticas - mas no Direito reintegrado na sua fonte eterna e na sua finalidade última e intangivel - o Bem Comum da Sociedade e do Universo, o Direito, como guarda do Bem Comum e não apenas como proteção ao Bem Próprio - eis o que nos ensina essa verdadeira filosofia da vida de que vindes ser nesta Faculdade, Sr. Alexandre Correia, o mais autorizado, o mais profundo, o mais lídimo representante.

E é êste o maior motivo do nosso júbilo. Não nos rejubilamos apenas, estudantes, companheiros e amigos vossos, por ver numa cátedra desta gloriosa Escola, ao lado de tantos nomes illustres, mais um homem de estudo, no verdadeiro sentido da expressão, cuja vida tem sido até hoje uma incorporação contínua de conhecimentos, que já hoje vos tornaram um sábio precocemente encanecido. Não nos rejubilamos por ver nessa cátedra um amigo e um mestre muito querido. Nossa maior alegria, aquela que faz de fato exultarem os nossos corações, é ver de novo iluminar as paredes deste venerável Instituto, colméia inesgotável do passado e do futuro intelectual de nossa terra, um representante autêntico dessa gloriosa filosofia perene, única que nos pode curar, nas próprias fontes do seu ensino, desse ceticismo jurídico, que vem ha tanto tempo corroendo as fibras íntimas da nossa estrutura jurídica e social.

Nas duas teses que apresentais, uma que vos deu a cátedra em que vos assentais, e outra que vos permitirá, porventura, bisar, um dia, com elegância, a vitória que alcançastes - em ambas se revela, não só a vossa grande erudição jurídica mas ainda a concepção sadia e cristã que possuís do que seja a ciência do bem comum, da justiça social, e não do bem próprio e do interêsse individual, como queria a concepção burguesa do Direito.

Mostrando como os romanos, êsses mestres imortais do Direito, já tinham alcançado, a exemplo dos gregos, uma concepção sadia e larga dessa ciência em sua tríplice expressão - positiva, das gentes, e natural - viestes lembrar, desde logo, a necessidade de combatermos esse preconceito contrário ao Direito Natural, que é um dos mais sérios causadores do descrédito a que tem chegado o Direito, na mente dos homens de nossos dias.

A reposição do Direito Natural, portanto, no posto de honra que lhe cabe, numa concepção verdadeira da ciência jurídica é tarefa 
a que, mesmo na cátedra especializada em que vos encontrais, podereis dedicar grande parte do vosso ensino.

Tanto mais quanto na segunda tese a que me referi, nessa substanciosa monografia que escrevestes sôbre a "escola histórica", mostrais luminosamente a falsa concepção do direito natural, contra o qual se insurgiu, com toda a razão, Savigny, - e que foi causa também em grande parte, de descrédito que lançaram sôbre essa parte fundamental do Direito, os positivistas e naturalistas juridicos da geração passada.

Ainda aí, com a sólida e excepcional preparação filosofica que possuís, tão rara em nossos meios intelectuais, podereis fazer um trabalho inapreciável em benefício das novas gerações. S. Paulo poderá, de ora avante, orgulhar-se de mais essa conquista. Ao mesmo tempo em que noutras capitais do pais conquistavam cadeiras funda. mentais da Falculdacle de Direito, espíritos apegados ainda aos preconceitos do individualismo Jurídico do século passado, e por isso mesmo antiquados, - abriram-se aquí em $\mathrm{S}$. Paulo as portas desta Faculdade, coberta de louros e de glórias, a um espírito moço e vigoroso, que não separará o Direito, da Vida, pois tem a inteligência iluminada por uma filosofta que não perde nunca o seu frescor e fornece ao Direito as bases para a sua integral reintegração na sintese total da verdade.

Confiamos, portanto, Sr. Alexandre Correia, na vossa atuação. As faculdades de direito são as grandes preparadoras dos homens publicos que amanhã virão tomar a direção do Estado Brasileiro. Se continuarem entregues ao ecletismo de um ensino agnóstico, individualista e sem consistência ou, peor do que isso, ao partidarismo dos adeptos da Revolução Marxista - teremos amanhã gerações de homens publicos sectários ou fanáticos, sem qualidades para dirigirem sàbiamente os destinos de nossa pátria.

Se, porém, o exemplo de S. Paulo frutificar e alguns homens como vós, $\mathrm{Sr}$. Alexandre Correia, tomarem conta das grandes posições do ensino do Direito em nosso país, poderemos, então, esperar confiantes por dias mais serenos para o futuro e a grandeza de nossa terra. 